\title{
La expansión de la frontera colonizadora en Guarayos, 1950-1970. El acceso a la tierra, base económica del poder local carai en las poblaciones guarayas*
}

\author{
The Expansion of the Colonizing Frontier in Guarayos, \\ the 1950-1970. Landholding Access, the Economic Basis \\ of Carai Local Power in the Guarayo Villages
}

\section{Pilar García Jordán}

ORCID iD: https://orcid.org/0000-0001-9187-1482

Universidad de Barcelona, España

Bajo la administración de la Intendencia Delegacional de Guarayos (Bolivia) surgió en la región un embrionario grupo dirigente blanco-mestizo, los carai, conformado por empleados públicos y colonos llegados a partir de 1938. El acceso a las tierras fiscales permitió a los carai consolidar su poder económico en el ámbito local guarayo, en particular tras la aprobación de la reforma agraria por el gobierno del Movimiento Nacionalista Revolucionario. El objetivo de este artículo es analizar los principales aspectos que presentó el acceso a la tierra desde la década de 1950 hasta 1970.

PALABRAS CLAVE: Bolivia; Guarayos; colonización; reforma agraria; poder local; frontera.

Under the administration of the Guarayos Delegation Intendancy (Bolivia) a new white-mestizo ruling group arose in the region: the carai, formed by public employees and settlers who arrived from 1938 onwards. By accessing to fiscal lands, this group could consolidate their economic power in the local Guarayo sphere, particularly after the approval of the agrarian reform enacted by the government of the Nationalist Revolutionary Movement (Movimiento Nacionalista Revolucionario). This paper aims to analyse the main aspects of the landholding access from the 1950s to 1970.

KeYwords: Bolivia; Guarayos; Colonization; Agrarian Reform; Local Power; Frontier.

Copyright: (C) 2021 CSIC. Este es un artículo de acceso abierto distribuido bajo los términos de la licencia de uso y distribución Creative Commons Reconocimiento 4.0 Internacional (CC BY 4.0).

* Este trabajo se inscribe en el proyecto I+D+i, Ref. PID2019-103879GB-I00 financiado por el Ministerio de Ciencia, Innovación y Universidades, y se desarrolla en el seno del Taller de Estudios e Investigaciones Andino-Amazónicos (2017SGR26). Algunos de los aspectos planteados aquí fueron presentados por la autora en el Simposio organizado por el TEIAA y el Instituto Francés de Estudios Andinos (Barcelona, 10 y 11 de diciembre de 2020). 


\section{A manera de introducción}

A lo largo del primer tercio del siglo XX la región de Guarayos (noroeste del departamento boliviano de Santa Cruz) fue percibida progresivamente por los cruceños como territorio propicio para la expansión de la frontera colonizadora. Son muchos los significados del concepto frontera que, inicialmente, han sido abordados por los geógrafos y vinculados a áreas limítrofes entre dos territorios pero que, más tarde, han sido abordados desde diversos ámbitos de las ciencias sociales. ${ }^{1}$ En la Bolivia republicana la categoría de frontera está estrechamente vinculada a la de la colonización. Por lo que se refiere a la primera cuestión, es un concepto que a lo largo del siglo XIX y primera mitad del siglo XX ha sido utilizado, en el plural de fronteras, para designar a los territorios periféricos ocupados por poblaciones indígenas no sometidas y en los que la presencia del Estado ha sido escasa si no, nula. Por lo que respecta la colonización, en el país andino-amazónico el vocablo ha servido para designar tanto la fundación de poblados por colonos como la explotación de los recursos naturales en regiones no controladas por el Estado; procesos ambos protagonizados bien por inmigrantes extranjeros, bien por nacionales sean estos miembros de la llamada sociedad criolla o de poblaciones indígenas. ${ }^{2}$

No puede sorprendernos pues que, en la década de 1930, coyuntura en la que los gobiernos bolivianos sostuvieron la necesidad de superar la crónica dependencia alimenticia del exterior, intelectuales y políticos señalaran el importante potencial agropecuario de la región. La cuestión era tanto más significativa si se consideraba el importante reservorio de mano de obra guaraya allí existente, que en 1938 se estimaba en 6.318 individuos. ${ }^{3}$ Valgan como ejemplos representativos los testimonios ofrecidos, primero, por el enviado gubernamental a la región, Noé Antelo, quien sostuvo, en 1937, que Guarayos podía convertirse en «el granero de Bolivia»; ${ }^{4}$ segundo, por los informes fechados en 1938, por un lado, por el teniente Rodolfo Clavijo, miembro de la delegación enviada por el gobierno Busch a mediados de

1 Reboratti, 1990. Londoño, 2003.

2 He abordado el análisis de ambas problemáticas en varias publicaciones, aunque para el caso de las políticas colonizadoras en Bolivia, remito a García Jordán, 2000. Por lo que se refiere a las políticas relativas a la expansión de la frontera (económica, social, política, cultural) desde una perspectiva comparativa para los casos de Bolivia y Perú desde la independencia hasta la década de 1940, véase García Jordán, 2001.

3 García Jordán, 2015, 56.

4 Informe del mayor Noé Antelo, La Paz, 1 de diciembre de 1937, Archivo Histórico Provincia Misionera San Antonio de Bolivia, Cochabamba (AHPMSAB), Archivo Misional de Guarayos (GAM), Fondo Cartas, año 1937, f. 276, recogido en Ibidem, 274-282. 
dicho año, quien informó al comandante en jefe del ejército, general Carlos Quintanilla, que la buena gestión del territorio y de la población guaraya permitiría abastecer anualmente un ejército de 22.000 hombres; 5 por otro, por Ovidio Barbery Ibáñez, quien en la memoria enviada a la Contraloría General, institución que lo había enviado a la región para hacer un inventario de los bienes existentes en la hasta entonces prefectura misionera de Guarayos, corroboró que la calidad de las tierras agrícolas existentes en la zona permitían al país tener allí «todo un granero», pues podrían producir hasta ciento cincuenta arrobas por hectárea en diversos productos, y había disponibilidad de pastos para mantener «más de 300.000 cabezas de ganado [que] abastecería en buen porcentaje las necesidades nacionales». ${ }^{6}$

La Intendencia Delegacional, surgida en Guarayos tras la secularización de las misiones, permitió el surgimiento en la región de un embrionario grupo dirigente blanco-mestizo, los carai, ${ }^{7}$ del que los primeros integrantes fueron aquellos que llegaron a la región como empleados públicos (oficiales y soldados, administradores, intendentes, secretarios y maestros, los más significativos) a partir de 1938. Con ellos arribaron también los colonos que, procedentes en su mayoría de otras zonas del departamento de Santa Cruz, vieron en la ocupación de las tierras fiscales, ${ }^{8}$ la principal vía de enriquecimiento económico. Los empleados públicos y los colonos hicieron del acceso a la tierra la principal estrategia económica que les permitió devenir grupo dirigente en el ámbito local guarayo; la consolidación de este se produjo tras la aprobación de la reforma agraria sancionada por el gobierno del Movimiento Nacionalista Revolucionario (MNR ${ }^{9}$ mediante el decreto del 2 de agosto de 1953, convertido en ley el 29 de octubre de $1956 .{ }^{10}$

5 García Jordán, 2015, 41. El texto fue reproducido en El Frente, Santa Cruz, en diversos números de 1940, el párrafo citado el 13 de septiembre de 1940, recogido en Ibidem, 291-298.

6 Informe del interventor de la Contraloría, Ovidio Barbery Ibáñez, La Paz, 21 de octubre de 1938, AHPMSAB, GAM, Fondo Cartas, año 1938, ff. 340-341, respectivamente, recogido en García Jordán, 2015, 302-309.

7 Carai o Karaí es el nombre dado por los guaraní hablantes, en este caso los guarayos, a los blancos.

8 La documentación de la época utiliza como sinónimos, los términos tierras fiscales, tierras baldías y tierras del Estado.

9 El MNR se conformó entre 1936 y 1944 aunque su primer programa político público se hizo en 1942. Entre sus integrantes se hallaron excombatientes de la Guerra del Chaco, periodistas e intelectuales reunidos en torno al periódico La Calle (La Paz) y un conjunto de abogados, altos funcionarios, profesores universitarios (Lavaud, 1998, cap. 1, 3). Una reciente reflexión sobre la emergencia del MNR y la Revolución de 1952, a partir del concepto de hegemonía postulado por Laclau y Mouffe, desde una posición postestructuralista en la que el indígena es percibido como campesino, es Estévez Rubín de Celis, 2019.

10 Decreto de 2 de agosto de 1953 y ley de 29 de octubre de 1956, medidas que pueden consultarse en la Gaceta oficial Estado Plurinacional de Bolivia, disponible en: http://www.gacetaoficial debolivia.gob.bo [Consultado: 12/01/2021]. 
Antes de avanzar con el análisis de las características que presentó la expansión de la frontera colonizadora en la región y el papel desempeñado por los carai en el escenario local guarayo, me interesa señalar el interés de la historiografía en estas últimas décadas por la historia social del poder y por la necesidad de recurrir al estudio del mismo en el ámbito local. Una crítica frecuente a los estudios realizados en el ámbito del poder en la historia contemporánea de España y de América Latina ha sido la escasa atención brindada a las relaciones existentes entre los grupos dirigentes, genéricamente denominados como élites, ${ }^{11}$ y el espacio en el que estas han asentado su poder; de ahí la demanda de investigaciones centradas en los poderes locales. ${ }^{12}$ En el caso específico de los países latinoamericanos, los trabajos en torno a dicha problemática han mostrado que el control de la tierra ha sido la base económica que ha permitido a los grupos dirigentes extraer su poder, básica pero no únicamente político; igualmente han mostrado que la tierra ha sido utilizada, en buena medida, para conformar unas redes clientelares cuyo escenario primero es el ámbito local. ${ }^{13}$ Este, en términos de espacio, será entendido aquí como el constituido por las relaciones socioeconómicas, la organización, la cultura y la práctica política desarrolladas al interior de dicho ámbito en un contexto histórico determinado y en territorios concretos, sean estos secciones municipales, cantones, municipios o unidades administrativas que recogen formas tradicionales de poder local tales como cabildos y capitanías. ${ }^{14}$

El objetivo de este artículo es el análisis de los principales aspectos que presentó el acceso a la tierra en la región de Guarayos desde la década de 1950 hasta el año de 1970, pues coincido con lo señalado por Romero Bonifaz que en las tierras bajas bolivianas, de las que forma parte la actual provincia de Guarayos, «la acumulación de poder económico y político se explica a partir del acaparamiento y concentración de tierras». ${ }^{15} \mathrm{La}$

11 No abordo aquí el debate en torno al uso de categorías utilizadas para denominar a los grupos dirigentes, sea élites o clase dominante. Una sucinta pero útil reflexión sobre las categorías de élite y clase social en Iuliano, 2010.

12 Díez Cano, 1999, 98.

13 Padua y Vaneph, 1986. Un estudio sobre la construcción del Estado en Brasil y Argentina y la ocupación de las llamadas «tierras nuevas» propone que el proceso de apropiación territorial, por parte de las —denominadas por la autora- oligarquías nacionales, fue parte integrante del proceso de concentración de poder y que la distribución de tierras públicas se realizó «a cambio de apoyo o alianza política, neutralizando así a los grupos oligárquicos rivales» (Osorio Silva, 2006, 65).

14 Diversas aproximaciones al fenómeno local en la América Latina contemporánea en Gallichio y Camejo, 2005.

15 Romero Bonifaz, 2003, 83. Coincido con Romero Bonifaz en señalar que el poder económico y político se articula en torno a la concentración de la tierra en pocas manos, cuestión que 
estructura de tenencia de la tierra es fundamental en la configuración de las relaciones sociales en el ámbito local de los pueblos de las otrora misiones guarayas de Ascensión, Urubichá, Yaguarú, Yotaú, San Pablo y de la población de El Puente, que formaban parte, en el período aquí estudiado, de la provincia Nuflo de Chávez (Mapa 1). Agreguemos que, según señala Soruco, en Santa Cruz no es posible pensar en la élite económica «sin la hacienda que configura un espacio no sólo económico sino social y cultural (de construcción identitaria de "nosotros" frente a "los propios", servidumbre indígena)» cuestión que — siempre según la autora— - se ve consolidada por la reforma agraria de $1953 .^{16}$

La hipótesis central que propongo demostrar aquí es que varios de los miembros del embrionario grupo dirigente carai surgido en Guarayos en la década de 1940 consolidaron su poder económico en las siguientes dos décadas cuando, tras la aprobación de la reforma agraria, accedieron legalmente a la propiedad de extensos lotes rurales. El análisis de los expedientes de solicitud de dotación y consolidación de tierras tramitados tras la aprobación de la medida, que constituyen las fuentes prioritarias de este trabajo, ${ }^{17}$ permiten sostener que, contrariamente a lo afirmado por algunos autores que señalan que la aplicación de la reforma agraria solo se hizo efectiva en Guarayos a partir de la década de 1970, tras la mejora de la vía carretera Santa Cruz de la Sierra-Trinidad, ${ }^{18}$ ya en la década de 1950 y, fundamentalmente, a lo largo de la década de 1960 se presentaron numerosas solicitudes de tierras. Los solicitantes fueron los miembros del citado grupo carai (empleados públicos y los primeros colonos llegados a la zona en la década de 1940), a los que se agregaron, en la segunda mitad de los cincuenta y a lo largo de la década de 1960, una nueva oleada de colonos. La vía utilizada para acceder a la tierra consistió, prioritariamente, en la ocupación de los terrenos para, en una fase posterior, solicitar la dotación y/o consolidación de los mismos; tierras dedicadas en su mayoría a la actividad ganadera bajo la fórmula de mediana propiedad. La tramitación

lleva consigo la explotación económica de la mano de obra rural, la exclusión política de la población indígena y campesina y la opresión cultural derivada de la imposición de un conjunto de prácticas homogeneizadoras que, en realidad, resultan discriminatorias. Ibidem, 85 .

16 Soruco, 2008, 33.

17 Los expedientes de dotación y consolidación de tierras seguidos tras el decreto/ley de reforma agraria y que afectan al departamento de Santa Cruz se encuentran en la sede cruceña del Instituto Nacional de Reforma Agraria (INRA); los expedientes relativos a la provincia Ñuflo de Chávez, de la que formaba parte la actual provincia de Guarayos, están recogidos en un total de 88 cajas, cada una de las cuales contiene entre 10 y 20 expedientes.

18 Véase, a título de ejemplo, Gwarayu mba'ekwasa, 2006, 73-74. 
y resolución de las solicitudes se vieron facilitadas por la existencia de una informal red social conformada en la década de 1940 en torno a los empleados públicos.

En consecuencia, en primer lugar haré una sucinta reflexión sobre lo acontecido en Guarayos en los años inmediatos a la secularización de las misiones (1938/1939) con el establecimiento de la Intendencia Delegacional de Guarayos; en segundo lugar, plantearé unas breves consideraciones historiográficas en torno a las reformas agrarias para centrarme en la reforma aprobada en 1953 por el gobierno del MNR; en tercer lugar, analizaré las características que presentó el acceso a la tierra de los empleados públicos y los colonos protagonistas de la expansión de la frontera colonizadora en la región en el marco temporal comprendido entre la década de 1950 y el año 1970.

\section{MAPA 1}

PROVINCIA ÑUFLO DE CHÁVEZ. LOCALIZACIÓN

DE LOS PUEBLOS GUARAYOS

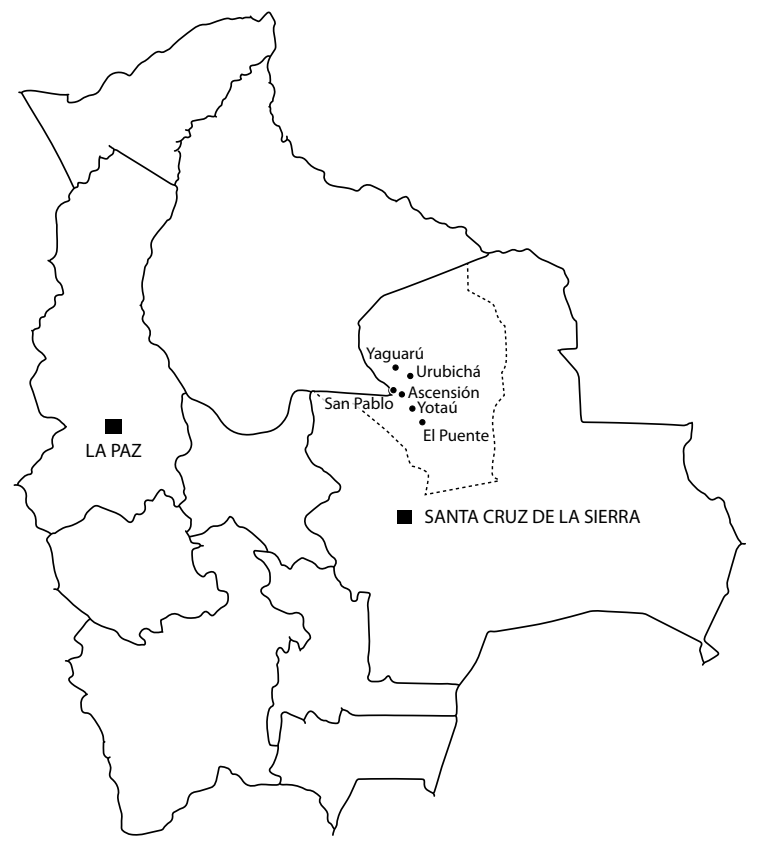

Fuente: Elaboración de Anna Guiteras Mombiola y Miguel Jiménez Vigara. 


\section{El Estado boliviano se hace presente en Guarayos, 1938/1939-1947/1948}

La secularización de los poblados misionales guarayos fue aprobada por dos decretos de 1938 y 1939, por los que se estableció la Delegación Nacional de Guarayos, más tarde Intendencia Delegacional, al frente de la cual, el delegado/intendente ejercería la máxima autoridad en el gobierno de la región, y que provocó el relegamiento de los misioneros, devenidos párrocos, al ejercicio exclusivo de las funciones religiosas. La creación de la institución fue resultado — según los textos legislativos- del interés del gobierno boliviano por completar el proceso de incorporación de «los indígenas en forma definitiva a la nacionalidad». ${ }^{19}$ El Estado se hizo así presente directamente en la región y el primer hito significativo fue la llegada a Guarayos, a fines de 1938 e inicios de 1939, del batallón Acre integrado por algo más de un centenar de miembros.

El gobierno de cada uno de los pueblos quedó a cargo del llamado administrador, representante del intendente delegacional y depositario del poder político, social y económico hasta entonces desempeñado por los franciscanos. Fueron estos administradores, individuos étnicamente blancos y mestizos, quienes dominaron el escenario local guarayo con prácticas frecuentemente corruptas denunciadas por políticos, funcionarios estatales y miembros significativos de la sociedad cruceña a lo largo de la década de 1940. Así, los primeros componentes del grupo dirigente carai surgido en los pueblos guarayos fueron los empleados públicos militares y civiles a los que se sumarían, progresivamente, los colonos blanco-mestizos atraídos por el «próspero futuro» económico que la nueva gestión de la región había augurado. ${ }^{20}$ Efectivamente, constatamos que por entonces se produjo la llegada de una variada tipología de individuos, que bien había frecuentado el camino existente entre la capital cruceña y Trinidad y conocían la potencialidad económica del territorio; bien aquellos otros que, aún sin conocer la región, supieron de la existencia de tierras fiscales y vieron la posibilidad de acceder a ellas y mejorar sus condiciones de vida. En suma, fueron los empleados públicos y los colonos quienes protagonizarían la expansión de la frontera colonizadora, de carácter agropecuario, en el noroeste cruceño. ${ }^{21}$

19 Art. 4 del Reglamento para la Intendencia de Colonización de Guarayos, Santa Cruz, 29 de abril de 1941, firmado por Víctor F. Serrano, delegado nacional de Colonias, AHPMSAB, Libro Azul, $14 \mathrm{ff}$.

20 Problemáticas que he analizado en García Jordán, 2015.

21 Frontera definida a partir de la explotación agraria y ganadera del territorio que comporta un determinado tipo de asentamiento, una sociedad y que en este caso me permite hablar de una frontera 
Las estrategias económicas utilizadas por los miembros del grupo dirigente carai fueron, por un lado, la actividad comercial tanto al interior de los pueblos como en los mercados regionales, cuestión que no trataré aquí dada la ausencia de fuentes que permitan hacer una rigurosa aproximación al tema; ${ }^{22}$ por otro lado, el progresivo acceso a la tierra para su explotación agrícola y/o ganadera. No obstante, los datos recogidos sean estimativos, dado que se perdieron gran parte de los registros, en el período 1943-1948 se presentaron primero ante la Intendencia Delegacional y más tarde ante el Instituto de Colonización, un mínimo de noventa y dos solicitudes de lotes (cuarenta y dos urbanos y cincuenta rurales) ubicados en los pueblos guarayos, lotes que habían sido ocupados por entonces o se tenía intención de hacerlo; cincuenta y nueve del total de solicitudes afectaban a Ascensión, principal población de la región, siguiendo a mucha distancia las peticiones de lotes en el resto de las localidades. ${ }^{23}$ Los lotes urbanos oscilaban entre los 150 y los $2.500 \mathrm{~m}^{2}$ y los rurales eran, generalmente, de $20 \mathrm{ha}$, aunque en algunos casos podían ser superiores a $500 \mathrm{ha}$.

El embrionario grupo dirigente en el ámbito local guarayo estuvo constituido, en primer lugar, por los administradores, algunos de los cuales habían llegado a la región como miembros del batallón Acre (diciembre de 1938). Esta unidad militar estaba compuesta por más de un centenar de individuos entre ellos el teniente Lino Soto, cuadros medios como Julio Rojas, Ovidio Barbery Justiniano, Alberto Reque, Herminio Peredo Vaca, Mario Justiniano Villarroel, Pedro Negrette, Juan Vázquez Claure, Querubín

colonizadora de carácter agropecuario. Reboratti (1990) ha abordado los aspectos generales del proceso en el que individuos y colectivos sociales se asientan sobre lo que denomina «tierras no ocupadas» o también «tierras nuevas», territorios «vírgenes» hasta entonces; acepciones estas que cuestiono porque, en la mayoría de los casos, como es el de las tierras bajas bolivianas, tales tierras estaban ocupadas por poblaciones indígenas no sometidas, autosuficientes, nómadas o seminómadas, que vivían de acuerdo a lo que se ha dado en llamar una economía natural.

22 Comerciantes importantes fueron a fines de la década de 1940 y en los años sucesivos Gregorio Rocha, Humberto Parra, Serafín Sansuste y Modesto Guaristi, aunque todos ellos, con excepción de Parra, con el paso del tiempo «no lograron adaptarse a las nuevas formas de comercio» y perdieron su protagonismo económico. Pereira Soruco, 2009, 99.

23 Los solicitantes fueron mayoritariamente varones que, por lo que respecta la actividad económica declarada, veintiocho dijeron ser agricultores, quince comerciantes —en algunos casos nos consta que ejercían ambas actividades_-, solo dos manifestaron ser ganaderos y tres funcionarios; había también dos ex-oficiales del Ejército, un sanitario y otros que señalaron ejercer diversos oficios. Por último, la mayoría de los arribados procedían del departamento cruceño, en particular Santa Cruz de la Sierra y de poblaciones cercanas a Guarayos, tales como Concepción, San Ramon, San Javier. Llegaron también colonos originarios de Cochabamba y del vecino departamento del Beni, además de unos pocos extranjeros procedentes de Italia y Alemania. Los expedientes relativos al período 1943-1948 se encuentran en Archivo y Biblioteca Nacionales de Bolivia, Sucre, Instituto de Colonización, 1. 176, t. I y II; 1. 228, t. I; 1. 609, t. I. Ver detalle de las solicitudes en García Jordán, 2015, 120-131. 
Faldín, y soldados rasos como Juan Vargas, Napoleón Suárez y Romelio Cortez Espinosa. ${ }^{24}$ En segundo lugar, formaron parte del grupo dirigente algunos de los intendentes delegacionales en la región como el citado Lino Soto y Fernando Justiniano Ruiz; y los maestros, entre ellos varios de los miembros de las familias Vaca, Aguilera y Añez. En tercer lugar, el grupo estuvo también conformado por algunos de los colonos que, procedentes de diversas provincias cruceñas, arribaron a la región a lo largo de la década de 1940; varios de estos colonos eran familiares de aquellos empleados o de antiguos colaboradores de las misiones (vaqueros, mayordomos, etc.) y ocuparon tierras en que desarrollaron actividades agropecuarias. ${ }^{25}$

La Intendencia Delegacional de Guarayos tuvo corta vida pues fue suprimida por el gobierno de Enrique Hertzog el 11 de diciembre de 1947, con efectos a partir del 1 de enero de 1948. La medida pareció inevitable tras las innumerables denuncias de corrupción de los empleados públicos, y del maltrato y la explotación de los guarayos a manos de aquellos. La supresión de la Intendencia supuso la plena incorporación de los pueblos guarayos a la organización político-administrativa de la provincia Nuflo de Chávez, ${ }^{26}$ la desaparición de los administradores reemplazados por los agentes municipales llamados corregidores y el acceso de los guarayos al libre ejercicio de sus derechos civiles sin tutela legal alguna. ${ }^{27}$

El gobierno Hertzog dictó, entre otras medidas relativas a la región, tres decretos, dos de los cuales afectan a la cuestión que aquí abordaré: Uno fue el sancionado el 11 de diciembre de 1947, que declaró la reserva de las tierras fiscales comprendidas en la jurisdicción de los cantones involucrados

24 Archivo Histórico de las Fuerzas Armadas, La Paz, Fondo Estado Mayor del Ejército.

25 Citemos, entre otros colonos, por orden alfabético a Andrés y Benjamín Añez, Ángel Añez Ortiz, Abel y Adolfo Añez Rivero, Ovidio Barbery Ibáñez, Walter Barba, Alcides Durán Rojas, Roberto Justiniano Ruiz, Adelaida Melgar Rojas, Severiano Menacho Coimbra, Gerardo Méndez Peña, Leonardo, Luciano y Leandro Negrette, Ramiro Ortiz Peña, Elva Ortiz de Serrate, Fernando Pacheco Urioste, Alberto Reque, Gregorio Rocha, Leonardo Sansuste, Valentin Schmidt, Pedro Serrate Parada, Néstor Suárez Justiniano, Román Suárez Suárez, Osmán y Sigfredo Vaca Jiménez, Ángel Vaca Recalde y José Vaca Saucedo.

26 La provincia Nuflo de Chávez, creada el 16 de septiembre de 1915, se vio afectada por la ley sancionada por el presidente Peñaranda el 19 de noviembre de 1943. A partir de entonces esa estuvo formada por los cantones de Padre Carvallo (pueblos de Yaguarú y Urubichá, siendo este último la capital); cantón Guillermo Añez (Yotaú, San Pablo y Ascensión, que sería la capital); Saucedo, cantón constituido por los rancheríos de La Gran Cruz, Madrecitas, El Sudán, Puerto Cachuela y otros determinados por la zona comprendida entre los ríos Grande y San Julián, con capital en Fortín Libertad (Anuario Administrativo, 1943; 1944, 3: 878). Fue en este último cantón donde surgiría el núcleo urbano de El Puente, que acabó dando nombre al cantón en los expedientes. Hago notar que, frecuentemente, tanto los solicitantes como los empleados que intervienen en los procesos asignan demarcaciones inexistentes, tales como cantón Ascensión, cuando en realidad la población es la capital del cantón Añez, o adscriben una población a un cantón equivocado.

27 García Jordán, 2015, 398-399. 
«y que no se hubieren constituido legalmente en propiedades particulares», salvando así las propiedades de los beneficiados por la corrupta política desarrollada por los administradores; tierras fiscales que el Ministerio de Agricultura, Ganadería y Colonización otorgaría a las familias guarayas «por lotes proporcionales al número de personas que las constituyan respetando en todo caso las posesiones actuales de los nativos» que no podrían ser enajenados en el plazo de diez años. Otro decreto fue el sancionado el 22 de enero de 1948 en el que se confirmaron las disposiciones recogidas en la medida anterior y en el que se introdujeron instrucciones varias a los ministerios, entre ellos la dirigida al de Agricultura para que vigilara que la propiedad a la que accedieran los guarayos, con sus correspondientes títulos legales, no pudiera ser «prendada, hipotecada ni vendida mientras los poderes públicos juzguen la oportunidad de acordar la plenitud de esos derechos», desapareciendo así el plazo de diez años fijados en el decreto anterior. En aplicación de tales medidas la Comisión Topográfica encargada de la adjudicación de lotes urbanos y rurales concedió un total estimado de 523 lotes, de los que 495 fueron otorgados a los guarayos (141 urbanos y 354 rurales); la extensión de cada lote rural osciló entre las 20 y las 50 ha. ${ }^{28}$ El tercer decreto fue el sancionado el 22 de abril de 1948 por el que se aprobó la creación de la Sociedad Cooperativa de Guarayos, constituida por las «poblaciones nativas» de los cinco pueblos que habían conformado la extinguida Intendencia Delegacional y que tuvo corta vida pues, solo dos años más tarde, fue suprimida por decreto de 30 de mayo de 1950 que dispuso, además, que los bienes de la misma serían rematados en subasta pública. Esta fue confiada a una Junta de Vecinos que, reunida en junio del mismo año, adjudicó, los bienes muebles e inmuebles, maquinaria y objetos varios ya a oficinas públicas, ya a los carai asentados en la zona. ${ }^{29}$

\section{La reforma agraria aprobada por el gobierno del MNR}

La crisis social, económica y política en la Bolivia de la década de 1940 propició el acceso al poder del presidente Víctor Paz Estenssoro, tras la revolución del 9 de abril de 1952 liderada por el MNR. ${ }^{30}$ Los puntos

28 Una reflexión sobre las estimaciones relativas a los datos consignados por la Comisión en García Jordán, 2015, 137-139.

29 Ibidem, 134-137 y 407-412.

30 Una excelente revisión historiográfica del movimiento revolucionario de 1952 es la realizada por Gotkowitz, 2011. 
fundamentales de la política nacionalista-reformista implementada por la nueva administración fueron el sufragio universal (21 de julio de 1952), la nacionalización de las minas (31 de octubre de 1952), y la reforma agraria (decreto 3464 de 2 de agosto de 1953, elevado a rango de ley el 29 de octubre de 1956). ${ }^{31}$

Las reformas agrarias en América Latina han sido objeto de atención por investigadores de diversas disciplinas que se han interesado por el significado, la magnitud y las características presentadas por las mismas. En general hay consenso en señalar, por un lado, la necesidad de tales reformas como vía para la superación de la pobreza por el campesinado y superar el escaso o nulo dinamismo de las economías agropecuarias incapaces, además, de proporcionar los alimentos necesarios a la población; por otro lado, que el fenómeno de la concentración de la tierra en grandes propiedades es una herencia colonial que se vio agudizada tras la independencia y el surgimiento de los Estados nación bajo el control de las oligarquías nacionales. ${ }^{32}$ Sorprende que la mayoría de los autores que han abordado, aunque fuera en forma tangencial, la reforma agraria en Bolivia, hablan de su implementación en el altiplano andino y valles periféricos; alguno llega incluso a sostener que en el oriente boliviano aquella nunca se aplicó. ${ }^{33}$

La reforma de la propiedad de la tierra en el campo boliviano había sido largamente demandada por las poblaciones quechua y aymara que en la década de 1920 incrementaron las movilizaciones en torno a la cuestión. Fue entonces cuando los trabajadores agrícolas del altiplano y de sus valles circundantes, vinculados a las grandes propiedades agrarias, reclamaron

31 Es amplia la bibliografía sobre las razones de la medida, el trámite legislativo y la implantación de la misma en el altiplano andino. Sin embargo, son pocos los estudios hechos sobre el impacto que tuvo el decreto y la ley en las tierras bajas; conviene señalar el trabajo inicial de Heath, Erasmus y Buechler (1969), en el que, tras abordar los aspectos generales de la reforma, analizan el impacto en las regiones de Chuquisaca y Tarija, tierras altas y valles tropicales, y el Oriente (Beni, Mojos y Santa Cruz). Más tarde, De Lucca y Mamani, 1974, estudiaron la incidencia de la reforma agraria, en particular en los fundos ganaderos cruceños. Posteriormente, Gill, 1987, analizó las contradicciones surgidas en el desarrollo de la reforma agraria en la región, estudiando tanto la inversión de capital y tecnología como el papel de la burguesía agroindustrial, los colonos y la progresiva proletarización de los campesinos. Trabajos posteriores analizaron con mayor profundidad el impacto de la reforma, entre otros, Arrieta et al., 1990; Pacheco y Miranda, 2001; Romero Bonifaz y Betancur, 2002; Romero Bonifaz, 2003; Sandoval Arenas et al., 2003. Trabajo reciente es el de Nobbs-Thiessen (2021) en el que se vincula estrechamente la expansión de la frontera colonizadora a la migración (interna y externa).

32 Entre otros trabajos con aproximaciones generales conviene citar a Bretón, 1994; Chonchol, 2003; Osorio Silva, 2006; Gómez, 2018. En el caso boliviano, y por lo que se refiere a las tierras bajas, véase la nota anterior.

33 Gómez, 2018, 211. Este autor señala que la reforma agraria boliviana, junto a la desarrollada en México antes y en Cuba, en la década de 1960 después, es considerada una reforma «clásica». 
insistentemente el acceso a la propiedad de la tierra para quienes la trabajaban. Señalemos, además, que la aprobación de la reforma agraria fue producto de su época cuando desde diversos planteamientos económicos se consideró que la pequeña propiedad no podía generar excedentes ni, por ende, riqueza nacional; de ahí el interés por impulsar la modernización agrícola. ${ }^{34}$ Hay consenso entre los investigadores en sostener que los principales objetivos de la medida fueron la redistribución de tierras; la supresión de todo tipo de servidumbre y la incorporación de la mano de obra «liberada» derivada de tal supresión al mercado; el aumento de la productividad; la reubicación de la población y la llamada Marcha hacia el Oriente que, proyectada por el gobierno de Enrique Peñaranda en 1942, asumió el MNR tras acceder al poder en $1952 .{ }^{35}$ Esta Marcha preveía la colonización de las tierras bajas que a diferencia de los planes proyectados en el pasado debía ser protagonizada, prioritariamente, por migrantes de tierras altas. ${ }^{36}$ Colonización que pasaba por la dotación de tierras individual y no colectiva, de forma que «los colonos podían insertarse en el mercado, comprar y vender sus tierras, $[y]$ diferenciarse internamente». ${ }^{37}$

Conviene aclarar que mientras la medida pretendía conseguir en el occidente del país la transformación de los latifundios existentes y el reparto de la tierra a los campesinos ${ }^{38}$ en el oriente cruceño, la reforma pretendía promover la modernización de las haciendas tradicionales que debían devenir empresas agrícolas. Es por ello que el decreto-ley fijó, entre otras cuestiones, por un lado, la existencia de diferentes tipos de propiedad, aunque las fundamentales fueron la pequeña, la mediana propiedad y la empresa; todas ellas podían ser agrícolas, ganaderas o mixtas. Mientras la pequeña

34 Soruco, 2008.

35 El Plan Bohan fue un modelo de desarrollo rural que, como ha señalado Romero Bonifaz (2003, 84 y 91-92), inspiró el contenido de la reforma agraria a aplicar en las tierras bajas, además de las políticas públicas que siguieron en los años sucesivos. Ver también sobre este plan y la Marcha al Oriente, Arrieta et al. 1990, 10-12; Sandoval Arenas et al. 2003, 14-16. Conviene recordar aquí lo señalado por Lavaud (1998, 354), a partir de Blasier (1971), que la revolución impulsada por el MNR fue apoyada desde el inicio por el gobierno de los Estados Unidos que otorgó subsidios directos por más de una década al Estado boliviano.

36 Un estudio de las políticas colonizadoras en Tierras Bajas en García Jordán, 2001, 268-277, 326 passim. Ver también el reciente trabajo de Nobbs-Thiessen, 2021.

37 Soruco, 2008, 60.

38 No puedo detenerme aquí en el uso de la categoría campesino que fue utilizada en forma creciente a partir de las décadas de 1930 y 1940 por corrientes de pensamiento que pretendían, con la asignación de tal categoría a los indígenas, la «integración» de estos al cuerpo de la nación. Como ha señalado Guiteras Mombiola $(2020,38)$ para el caso boliviano, el objetivo a lograr era la «forja de un "indio" campesino, orientado hacia el mercado y la propiedad individual e "integrado" a la nacionalidad». 
propiedad tenía que cumplir una «función social» garantizando la reproducción de las unidades domésticas «campesinas», la mediana propiedad y la empresa agropecuaria debían cumplir una «función económico-social». ${ }^{39}$ Por otro lado, la superficie de las propiedades dependía ya de la zona geográfica que en el caso de Guarayos era la denominada zona subtropical de Santa Cruz; ya del tipo de explotación, agrícola o ganadera. La superficie de la pequeña propiedad no podía superar las 50 ha (agrícola) y las 500 ha (ganadera); la mediana propiedad, las 500 ha (agrícola) y 2.500 ha (ganadera); la empresa agrícola no debía superar las 2.000 ha y la gran empresa ganadera las 50.000 ha siempre que albergara 10.000 cabezas de ganado mayor. ${ }^{40}$

Las investigaciones relativas al impacto de la reforma agraria en las tierras bajas han sostenido, en líneas generales, que en el caso del departamento cruceño la aplicación de la medida reformista provocó la ampliación de la superficie cultivada con el desarrollo de un sistema productivo que posibilitó la concentración de la tierra que, frecuentemente, contó con la concesión de créditos agropecuarios. ${ }^{41}$ Ampliación de la tierra agrícola que estuvo vinculada a una transformación del sistema de tenencia de la tierra de tal magnitud que ha llevado a algún autor a sostener que la medida reformista propició «una revolución agraria democrática campesina». ${ }^{42}$

Las solicitudes de dotación y de consolidación de tierras ${ }^{43}$ seguían un trámite bien conocido que pasaba por la petición del fundo, su admisión por el juzgado agrario móvil, la audiencia de inspección ocular del lote y la sentencia del juez. El trámite comportaba la participación a lo largo de esta primera instancia del proceso de diversos actores (juez, secretario,

39 El desarrollo de la empresa agrícola requería, entre otras cuestiones, la introducción de tecnología moderna, capital y la contratación de mano de obra asalariada, elementos todos ellos que permitirían aumentar la producción de alimentos para el mercado interior y, al mismo tiempo, la generación de excedentes destinados a la exportación. Ver Romero Bonifaz, 2003, 95 passim; Sandoval Arenas et al., 2003, 41 passim.

40 Extensión de la propiedad agrícola en cap. III, arts. 15 a 17, y de la propiedad ganadera en cap. IV, art. 21, de la ley de 29 de octubre de 1956. Ticona $(2004,6)$ sostiene que la ley fue ambigua con ayllus y poblaciones originarias pues no proporcionó mejoras a los comunarios pero toleró su reproducción como sistema socioeconómico y político.

41 Sandoval Arenas et al., 2003, 44.

42 Antezana, 2011, 29.

43 La ley de reforma agraria señaló tres formas para la concesión de tierras: La primera era la dotación cuando la tierra otorgada era baldía, fiscal; la segunda era la consolidación cuando el solicitante de la tierra la había ocupado antes de 1953; finalmente, la afectación era aquella tierra no trabajada por el propietario. Esta última, pensada inicialmente para las grandes propiedades existentes en tierras altas y valles periféricos, se aplicaría también en tierras bajas en el supuesto que los lotes rurales hubieran sido adjudicados a personas o entidades, pero no hubieran sido explotadas. 
topógrafo, colindantes, corregidor y, en algunos casos, también un abogado). ${ }^{44}$ En caso de sentencia favorable, la sección departamental del Consejo Nacional de Reforma Agraria (CNRA) ${ }^{45}$ examinaba el expediente y se remitía a la sede central de la institución en La Paz donde, tras las revisiones correspondientes y el informe jurídico preceptivo, pasaba a las Salas Primera o Segunda del CNRA, encargadas de aprobar o rechazar la sentencia en primera instancia a través del llamado auto de vista. Si este era favorable, el expediente pasaba a la consideración de la Presidencia de la República, a través del ministerio de Asuntos Campesinos, que mediante una resolución suprema, concedía la dotación y/o consolidación de las tierras y la expedición de los correspondientes títulos ejecutoriales, esto es, los títulos de propiedad definitivos. ${ }^{46}$ Llegado este momento, la emisión de tales títulos podía encontrar algunos obstáculos como consecuencia de diversas revisiones que, en ocasiones, retrasaban la expedición de aquellos por varios años.

Un cambio significativo en el proceso de solicitud de tierras se produjo bajo la presidencia de René Barrientos Ortuño (1964-1969) cuando se aprobó, por decreto supremo 7985 de 3 de mayo de 1967, la creación de las Brigadas Móviles. La medida pretendía concluir el proceso de reforma agraria que, según la ley, había sido el compromiso del gobierno de Barrientos. ${ }^{47}$ Las Brigadas Móviles debían actuar de oficio en la dotación de tierras a quienes ocuparan fundos que no habían sido sometidos a proceso agrario alguno; de acuerdo a tales planteamientos, fueron las Brigadas las

44 Los jueces agrarios que, entre otras funciones, eran los llamados a dilucidar los procesos de afectación y dotación de tierras según el decreto-ley reformista, eran elegidos por el presidente de la república a propuesta del CNRA.

45 Consejo que fungía como tribunal judicial superior que, además de las funciones administrativas correspondientes (cooperativismo, créditos, colonización, etc.), tuvo «como un rol fundamental el de conocer en grado de apelación las acciones sobre denuncia de tierras» (Armijo Paz, 2017, 176).

46 El desarrollo de la audiencia de inspección ocular de los fundos contemplaba la secuencia siguiente: tras confirmar la presencia en los mismos de las autoridades judiciales, el solicitante, los colindantes y los vecinos interesados, el juez daba la palabra al demandante que solía ratificar el contenido de su solicitud, se constataba el carácter agrícola, ganadero o mixto del fundo y las actividades económicas del mismo (cultivos, ganados y eventual comercialización de los productos obtenidos), las «inversiones» hechas (casa vivienda, corrales, potreros, etc.) y utensilios utilizados y, por último, se daba la palabra a los eventuales colindantes y vecinos con vistas a averiguar si alguno de ellos se oponía a la solicitud; el topógrafo, que también debía asistir al acto, era el encargado de realizar el plano y el informe pericial del fundo. Las solicitudes de dotación y/o consolidación de tierras dedicadas a la explotación ganadera debían incorporar también al expediente el certificado del registro de marca del ganado del titular de la petición.

47 Según Romero Bonifaz (2008, 117), fue bajo el gobierno de Barrientos (1964-1969), junto a los gobiernos del coronel Hugo Banzer (1974-1978) y de Jaime Paz Zamora (1989-1993) los que repartieron el $60 \%$ de la tierra distribuida por el Estado boliviano. 
que formalizaron los trámites agrarios que en el caso de los pueblos guarayos afectaron, en buena medida, a las tierras ocupadas por las poblaciones originarias.

\section{Los empleados públicos y los colonos, protagonistas de la expansión de la frontera agropecuaria}

Los carai arribados a Guarayos durante la administración de la Intendencia Delegacional y en los años sucesivos fueron los primeros que accedieron a las consideradas tierras fiscales. Por entonces, la praxis usual relativa a la tierra consistió en la ocupación de los terrenos sin la mediación de trámite administrativo alguno; este solo se realizaba bien cuando el ocupante supiera de la intención o existencia de otro interesado en acceder a las tierras por él ocupadas; bien cuando se pretendía especular con la tierra, que permanecía sin explotar, procediendo a la venta de la misma para lo que se requería, como mínimo, demostrar la posesión que no era lo mismo que tener el título legal de propiedad de aquella sino que implicaba, normalmente, haber explotado la tierra ocupada. Si ese no era el caso, un colono podía ocupar parcial o totalmente aquel lote y pedir la dotación dando lugar a la «afectación» de la tierra al antiguo poseedor por haber incumplido con la ley y, por ende, esa era revertida al Estado que la concedía al solicitante que sí había desarrollado en ella actividades productivas.

Las solicitudes de dotación y/o consolidación de tierras ubicadas en el territorio jurisdiccional de las poblaciones guarayas ascendieron en el período 1957-1970 a un total estimado de cuarenta y dos (Cuadro 1); ${ }^{48}$ la reducida cantidad no debe enmascarar el hecho que el número de ocupantes de tierras fue, sin duda, muchísimo mayor si bien no consideraron necesario formalizar la solicitud por las razones antes señaladas. ${ }^{49}$

Analicemos pues los expedientes localizados relativos al territorio jurisdiccional de la actual provincia de Guarayos que, como se ha dicho, formaba parte en los años aquí estudiados de la provincia Nuflo de Chávez. Una mirada al cuadro adjunto nos permite observar las diferencias respecto

48 Según De Lucca y Mamani $(1974,69)$ fueron 137 los títulos otorgados en la provincia Nuflo de Chávez.

49 Los expedientes analizados permiten ver la existencia de muchos colindantes de las tierras solicitadas en dotación, que son las analizadas aquí, que en el período estudiado no tramitaron la solicitud de las tierras por ellos ocupadas. 
a lo acaecido en la década de 1940; por entonces, del total de cincuenta lotes rurales solicitados, veinticuatro de los demandantes declararon tener la intención de ocupar los terrenos, catorce dijeron haberla ocupado e ignoramos los datos de doce de ellos. ${ }^{50}$ Por el contrario, entre los años 1957 y 1970, todos los solicitantes manifestaron haber ocupado la tierra un tiempo antes, ninguno señaló su intención por ocupar la tierra y tres declararon haber comprado la tierra a alguien que tenía posesión de la misma.

\section{CUAdRo 1}

SOLICITUDES DE LOTES RURALES EN GUARAYOS, 1957-1970

\begin{tabular}{|c|c|c|c|c|}
\hline Años & Intención & Ocupación & Compra & Total \\
\hline 1957 & 0 & 3 & 0 & 3 \\
\hline 1961 & 0 & 3 & 1 & 4 \\
\hline 1962 & 0 & 3 & 0 & 3 \\
\hline 1963 & 0 & 0 & 1 & 1 \\
\hline 1964 & 0 & 2 & 0 & 2 \\
\hline 1965 & 0 & 1 & 0 & 1 \\
\hline 1966 & 0 & 2 & 1 & 3 \\
\hline 1967 & 0 & 11 & 0 & 11 \\
\hline 1968 & 0 & 7 & 0 & 7 \\
\hline 1969 & 0 & 3 & 0 & 3 \\
\hline 1970 & 0 & 4 & 0 & 4 \\
\hline Total & 0 & 39 & 3 & 42 \\
\hline
\end{tabular}

Fuente: Elaboración propia. ${ }^{51}$

Antes de avanzar con el análisis de la información recogida en los expedientes conviene señalar que todas las solicitudes presentadas obtuvieron la aprobación, en primera instancia, del juzgado agrario móvil. Las sentencias, como documento legal que eran, recogían puntualmente todos los datos consignados a lo largo del proceso recogidos en la solicitud, acta de audiencia de inspección ocular, informe pericial del topógrafo

50 García Jordán, 2015, 113 passim.

51 Archivo del Instituto Nacional de Reforma Agraria de Santa Cruz, Santa Cruz (AINRA. SC), exps. 4669, 5030, 8190, 8368, 8474, 8481, 8771, 9155, 9348, 10646, 11401, 12002, 14024, 14089, $15272,15394,15713,15808,15809,17303,17309,17310,17312,17347,17350,17355,17389,17550$, 17951, 18346, 18362, 19303, 20731, 21294, 21632, 21902, 26852, 27224, 27225, 29545, 30770, 37524. 
y recurrían, con mayor o menor detalle a los artículos de la legislación a partir de los cuales se emitía la sentencia, haciendo referencia a la función social o económico social, máxime cuando «se trata de colonizadores que están habitando esas zonas alejadas y despobladas, que necesitan la mano del hombre $[\ldots] \gg .{ }^{52}$

Sin desmarcarse de estos propósitos, algunas de las sentencias se hicieron eco explícitamente del proyecto socioeconómico y político implementado por el gobierno del MNR, del que era buen reflejo la ley agraria, cuando señalaron que la dotación de tierras se hacía de acuerdo con los planes del «actual Gobierno en lo tocante al incremento de la producción pecuaria, resulta que el solicitante con su trabajo y esfuerzo personal e inversión de capital suplementario ha hecho que las tierras que ocupa, cumplan con una función social y económicamente útil a la colectividad y al Estado». ${ }^{53}$ Inversión de capital del que formaba parte, en el caso de propiedades ganaderas, la construcción de la casa habitación para el alojamiento de la familia y, si era el caso, de casas para los empleados; la existencia de ganado (fundamentalmente vacuno y caballar pero también cabrío y porcino) y la plantación de pastos para su alimentación, corrales para el marcado de las reses, alambrado de una parte del terreno y, en el caso de producción de quesos y mantequilla, los útiles necesarios para la transformación de la leche. En la mayoría de las solicitudes se señalaba que los trabajos eran efectuados por los demandantes y sus familiares que contaban también, en general, con el concurso de vaqueros y peones asalariados que podían ser fijos en la estancia o contratados para la realización de determinadas actividades (vacunación, marcado de las reses, etc.). ${ }^{54}$

52 Palabras del juez Alfredo Mogrovejo R. en la sentencia favorable a la solicitud de dotación de tierras de Ramón Arredondo Justiniano en 1962, en AINRA.SC, exp. 8771, ff. 3r-8v. El énfasis es mío. El juez Mogrovejo incluyó frecuentemente en sus sentencias la referencia a la importancia de la colonización en la región; valga como ejemplo lo señalado en AINRA.SC, exp. 9155, f. 10r.

53 Sentencia del juez Leopoldo Eiz Otazú fallando favorablemente la solicitud hecha por Óscar Arandia Vaca a fines de 1966, del fundo El Chorro, en AINRA.SC, exp. 17355, f. 13r. La mención figura en diversos expedientes; valgan como ejemplo las sentencias dictadas por el juez Gonzalo Osinaga Zeballos, una en 1968, favorable a la solicitud de Carlos Sosa López, en la que aquel argumentaba que el fundo contribuía con sus productos ganaderos a «los planes del actual Gobierno» favoreciendo el «autoabastecimiento y por ende a la economía nacional» y cumpliendo con ello satisfactoriamente con la «función social y económicamente útil a la colectividad» prevista por la ley de reforma agraria; otra relativa a la petición de Julio Rojas Apamaita, en 1970 en AINRA.SC, exp. 17312, ff. 12-14 y exp. 26852, f. $15 v$.

54 En algunos casos se mencionaba explícitamente la existencia en el fundo de un mayordomo o capataz a sueldo como vemos en la solicitud efectuada por Dorys Suarez Coimbra en 1967, en AINRA.SC, exp. 18346, ff. 5-6v. En el caso de propiedades agrícolas se contaba con los útiles necesarios para el trabajo. 
Los datos contenidos en los expedientes de las cuarenta y dos solicitudes de tierras presentadas entre 1957 y 1970 permiten hacer algunas reflexiones sobre los individuos solicitantes, su adscripción al grupo de empleados que ocuparon cargos públicos en la década de 1940 o bien a los colonos que empezaron a llegar por entonces, así como el lugar de nacimiento de todos ellos y su actividad laboral; la ubicación de los lotes de tierras y el acceso a las mismas (ocupación, intención o compra); el tipo (pequeña, mediana o gran propiedad o empresa ganadera) y las características de la misma (agrícola, ganadera, mixta).

Así, por lo que se refiere a la adscripción de los solicitantes a uno u otro grupo (empleados y colonos), como mínimo doce de ellos habían sido empleados públicos o familiares de estos en la década de $1940 ; 55$ los colonos fueron un total de veintinueve y una solicitud fue la presentada por un sindicato agrario, ${ }^{56}$ que vio como demandantes a noventa campesinos agrupados en el Sindicato de San Pablo. Además, se ha constatado que diversos miembros de una familia (hijos y hermanos) solicitaron fundos, en muchos casos colindantes entre ellos, como muestran los expedientes de los Justiniano Ruiz, Parra Ugarte y sus hijos, Rocha Coca y sus hijos, la familia Arandia Vaca o los hermanos Suárez Coimbra. ${ }^{57}$

Siempre a propósito de los solicitantes interesa señalar tanto el lugar de nacimiento o procedencia de los mismos como la actividad laboral a la que dijeron dedicarse en el momento de la petición. Si bien ignoramos el lugar de origen de veinte de los peticionarios, sabemos que, como mínimo, diecinueve de ellos procedían del departamento de Santa Cruz (once de la capital, el resto de diversos cantones y en el caso de los miembros del

55 El número aumentará cuando pueda confirmar el parentesco de los solicitantes pues sospecho que algunas mujeres demandantes de lotes eran esposas de empleados públicos; es el caso de Esperanza Justiniano, que aquí he incluido como colona, que intuyo fue esposa de uno de los intendentes delegacionales, Román Suárez, aunque este es un dato que no he podido verificar por el momento.

56 Los sindicatos agrarios bolivianos, muy diferentes a los sindicatos obreros, pueden ser definidos como una «organización productiva y social manejada por la comunidad para regular las relaciones internas y externas» cuyas decisiones son tomadas por la asamblea comunal y, generalmente, se agrupan en subcentrales, en ocasiones siguiendo los límites cantonales; tales subcentrales se agrupan a su vez en centrales de las que forman parte aquellas existentes en la provincia; finalmente, las centrales se agrupan en federaciones departamentales (Machicado, 2010, 10). Pereira Soruco $(2009,114)$ sostiene que los sindicatos agrarios surgieron en Guarayos a partir de 1975 impulsados por el despecho del MNR tras haber sido expulsado del gobierno de Bánzer; agrega que la iniciativa del MNR obedeció, además, al interés del partido en mantener la hegemonía entre los guarayos y la creciente corriente migratoria de colonos procedentes de otras zonas del país.

57 AINRA.SC, exps. 14024 y 17951 relativos a los Justiniano Ruiz; 15713, 17309 y 17310 de la familia Parra; 29545 y 30770 de la familia Rocha; 17355, 27224 y 27225 de los Arandia Vaca; 18346 y 21902 referidos a los hermanos Suárez. 
Sindicato San Pablo habían nacido en el pueblo homónimo en su mayoría), dos eran originarios del Beni y uno de Cochabamba. Por lo que se refiere a la profesión o actividad a la que dijeron dedicarse, diecisiete declararon ser ganaderos (dos de ellos industriales ganaderos), seguidos a cierta distancia por ocho que dijeron ser agricultores y ganaderos, cinco agricultores como eran también los guarayos agrupados en el citado Sindicato, un comerciante, un agrónomo, a los que debemos agregar los diez solicitantes que no declararon actividad alguna lo que no implica que no ejercieran algún oficio.

Por lo que respecta la ubicación de las tierras solicitadas, más del $50 \%$ estaban situadas en el territorio jurisdiccional del cantón Añez, prácticamente todos en los alrededores de Ascensión (veinte lotes), además de un lote en Yotaú y otro, el demandado por el Sindicato, en los alrededores de San Pablo. Le seguían en número las peticiones de tierras ubicadas en el cantón Carvallo (diez en Yaguarú y tres en Urubichá). Por último, fueron siete los lotes de terrenos situados en el cantón Saucedo, todos ellos en El Puente.

Por lo que se refiere al acceso a las tierras demandadas (ocupación, intención o compra), las solicitudes incluyeron, generalmente, la fórmula «vengo poseyendo en forma continuada y pacífica una posesión en tierras baldías». ${ }^{58} \mathrm{Y}$ prácticamente todos los peticionarios, con excepción de tres de ellos que declararon haber obtenidos los lotes tras la compra a sus antiguos poseedores, dijeron haberlos ocupado «tiempo atrás», «varios años atrás», «muchos años atrás» y, solo en algunos casos, mencionaron el año en que lo hicieron. Como señaló el juez Gonzalo Osinaga Zeballos en la sentencia favorable a la petición de dotación de tierras efectuada en 1968 por Humberto Parra Ugarte, este «al igual que casi todos los ganaderos de la zona se estableció en estas tierras desde hace muchos años». ${ }^{59}$ La cuestión no es baladí pues, como se ha mencionado, las tierras ocupadas antes de 1953 daban derecho a solicitar no solo la dotación sino también la consolidación de las mismas. Además, en algunos casos, los solicitantes señalaron que con su petición pretendían, al amparo de la ley agraria, «legalizar su derecho posesorio» ${ }^{60}$ Una variante significativa es la representada por los guarayos agrupados en el Sindicato San Pablo quienes declararon en su

58 Así consta, por ejemplo, en la solicitud de dotación presentada por Ramón Arredondo Justiniano en 1962, en AINRA.SC, exp. 8771, f. 1r.

59 AINRA.SC, exp. 17310, f. 12v.

60 Valga como ejemplo lo señalado por Óscar Arandia Vaca en su petición del 2 de diciembre de 1966 del Fundo El Chorro, que declaró ocupar desde quince años atrás, en AINRA.SC, exp. 17355, f. $1 \mathrm{r}-\mathrm{v}$. 
solicitud que el objetivo de la misma era «legalizar sus derechos propietarios de las tierras que poseen». ${ }^{61}$

Conviene aquí hacer un inciso sobre la solicitud de dotación de las tierras que habían sido compradas a sus poseedores $;{ }^{62}$ en los casos trabajados, dos afectan a individuos que habían llegado a Ascensión en la década de 1940; uno fue Alberto Reque, quien se había visto beneficiado por el lote en 1943 en el que, aparentemente, no había desarrollado trabajo alguno y que vendió a un colono en fecha no determinada. ${ }^{63}$ Otro fue el lote comprado por Ernesto Mercado Menacho a Emiliano Cuéllar, quien, había ocupado una importante extensión de tierras en $1954 .{ }^{64} \mathrm{~A}$ diferencia de las compraventas anteriores, la tercera afectó a un lote de casi 2.000 ha ubicadas en Yotaú, cuyos «derechos de posesión» había recibido en 1964 Alcides Durán Rojas, un antiguo colaborador de las misiones y vecino de Yotaú por un tiempo; ${ }^{65}$ aunque no se menciona explícitamente es evidente que tales derechos habían sido obtenidos tras la venta del lote. ${ }^{66}$ Finalmente, la primera y única solicitud hecha por los guarayos fue la presentada en 1968 por el Sindicato San Pablo conformado por alrededor de noventa familias que trabajaban las tierras por ellos ocupadas tradicionalmente en las cercanías del pueblo del mismo nombre. ${ }^{67}$

Por lo que respecta la extensión de los lotes y la explotación económica de los mismos, veinticuatro de ellos fueron categorizados como mediana propiedad y once como pequeña propiedad, todos dedicados a la ganadería. ${ }^{68}$

61 Solicitud presentada en diciembre de 1968 en AINRA.SC, exp. 20731, f. 3r-v.

62 El poseedor de la tierra tenía el disfrute de la misma, pero, en derecho, no tenía el título legal como propietario. No obstante, fueron muchos los lotes poseídos por titulares y que no aparecen en las fuentes, que fueron objeto de compraventa. Por el momento no estoy en condiciones de señalar, en modo preciso, las características de tales compraventas.

63 Reque había llegado a Guarayos como miembro del batallón Acre a fines de diciembre de 1938 y junto a otro conmilitón, Herminio Peredo solicitó, y obtuvo, el 24 de julio de 1943 la dotación de un lote rural, La Cruz de 45 ha (García Jordán, 2015, 120).

64 Cuéllar había sido administrador por breve tiempo, en 1937, de Urubichá y Yaguarú, durante los meses que los misioneros habían debido desplazarse a Santa Cruz llamados por la autoridad judicial (Ibidem, 25 passim y 102).

65 El inspector general de Colonias, Nataniel Prado Barrientos, en la visita realizada a Guarayos en 1945 no dudó en incluir a Durán, del que dijo haber ejercido por un tiempo la subadministración de Yotaú, entre los abigeatistas que bajo la administración de la Intendencia Delegacional se habían apropiado del ganado existente en las misiones (Ibidem, 394).

66 AINRA.SC, exps. 8368, 10646 y 17389 respectivamente.

67 Solicitud firmada por Ramón Abae Machico, Pedro Tayandy Rebañe y Pedro Aricari Tamacuine, secretarios general, de actas y de hacienda respectivamente en AINRA.SC, exp. 20731, f. 3r-v.

68 El número total de cabezas de ganado vacuno existente en la mediana propiedad ganadera aquí analizada osciló entre las 150 reses y las 720, aunque la mayoría acogieron un número estimado entre 300 y 500 reses. La pequeña propiedad ganadera difícilmente superaba las 100 reses. 
El resto de lotes fueron reconocidos como pequeña propiedad agraria (tres lotes) - siendo uno de ellos el terreno correspondiente al Sindicato San Pablo- y dos lotes de pequeña y otros dos de mediana propiedad mixta, agrícola y ganadera (Cuadro 2). ${ }^{69}$

\section{CUADRO 2}

SOLICITUDES DE TIERRAS POR ACTIVIDAD PRODUCTIVA Y EXTENSIÓN, 1957-1970

\begin{tabular}{|c|c|c|c|}
\hline Actividad productiva & Tipo propiedad & Número & \multirow{2}{*}{ Total } \\
\hline \multirow{4}{*}{ Ganadera } & Pequeña & 11 & \multirow{2}{*}{35} \\
\cline { 2 - 3 } & Mediana & 24 & \multirow{2}{*}{3} \\
\cline { 2 - 3 } & Grande & 0 & \multirow{2}{*}{3} \\
\hline \multirow{3}{*}{ Agrícola } & Pequeña & 3 & \multirow{2}{*}{4} \\
\cline { 2 - 3 } & Mediana & 0 & \multirow{2}{*}{4} \\
\cline { 2 - 3 } & Grande & 0 & 42 \\
\hline \multirow{3}{*}{ Mixta } & Pequeña & 2 & 0 \\
\cline { 2 - 3 } & Mediana & & \\
\cline { 2 - 3 } & Grande & & \\
\hline
\end{tabular}

Fuente: Elaboración propia.

Una cuestión que emerge en el análisis de las fuentes es el mercado en el que se comercializaban los productos obtenidos en los fundos agropecuarios. En función de la mayor o menor extensión de las explotaciones ganaderas, he constatado que la mayoría de las propiedades medianas declararon colocar sus productos (carneado de reses y, en ocasiones, quesos y mantequilla) en la capital cruceña e incluso, en algunos casos, en los mercados de los departamentos cercanos ${ }^{70}$ las pequeñas propiedades ganaderas colocaron su producción (leche, mantequilla y quesos) en los mercados locales de

69 Cada titular recibió en concesión individual un lote de 50 ha circa, que fue considerado pequeña propiedad agrícola, en AINRA.SC, exp. 20731.

70 Raramente los expedientes incluyen datos cuantitativos de la producción por lo que son útiles los datos consignados relativos al fundo El Socorro (2.695,88 ha) en el que había 500 vacunos y 48 reproductores de raza cebú, propiedad de Esperanza Justiniano de Suárez. Este fundo comercializaba al año 300 @ de queso y alrededor de 150 cabezas de ganado vacuno macho, según consta en AINRA SC, exp. 11401, f. 6r-v. La referencia a los mercados de la «capital» (Santa Cruz) o en el «interior del país» son frecuentes como vemos en AINRA.SC, exp. 17312, ff. 6-7 o el exp. 21294, ff. 7-13. 
las poblaciones guarayas. Estos mercados locales fueron también el destino de los excedentes agrícolas (arroz, maíz, yuca, plátano prioritariamente) o ganaderos de los productos obtenidos en las propiedades agrícolas o mixtas.

Llegando al final de este apartado, considero útil detenerme en tres solicitudes de dotación y consolidación de tierras que, desde mi punto de vista, son ilustrativas de la mayoría de los puntos abordados pues involucran a empleados públicos y colonos, los relativos a la familia Justiniano Ruiz. ${ }^{71}$

La primera solicitud es la presentada el 6 de enero de 1969 por Fernando Justiniano Ruiz, abogado, quien estuvo durante algunos meses del año 1940 al frente de la Delegación Nacional de Guarayos. El demandante, nacido en Santa Cruz y que declaró ser agricultor y ganadero, dijo haber establecido treinta años atrás (1939) el establecimiento ganadero Quebrada Blanca, con una extensión aproximada de 3.500 ha, en El Puente, «manteniendo posesión pacífica, continuada e ininterrumpida» del bien rústico. El fundo limitaba con tierras fiscales, el arroyo Surucusi y el río San Julián y no había en él asentamientos previos. La explotación contaba con 720 cabezas de ganado vacuno, 30 de caballar y 150 de lanar, lo que exigía la presencia de corrales, chiqueros, potreros cercados con alambrado; disponía además de una casa-vivienda y con cultivos destinados al consumo familiar en una superficie aproximada de 8 ha. Sostuvo, igualmente, que los productos obtenidos (quesos y carne) eran comercializados en los mercados cruceños y del interior de la república. La petición concluía demandando la dotación y consolidación del fundo.

La tramitación de la solicitud siguió todos los pasos necesarios en esta primera fase y transcurrido solo un mes, el 10 de febrero de 1969, el juez Calixto Arancibia Sena, tras considerar probados todos los extremos y reconocer la inversión realizada en el fundo que, dijo, era «útil a la colectividad y al propio desarrollo económico del país, haciendo al mismo tiempo, que aquellas tierras cumplan una función social de positivo beneficio colectivo» ${ }^{72}$ resolvió aprobar la dotación y consolidación del fundo. Quebrada Blanca fue declarado mediana propiedad ganadera no obstante superar ampliamente las 2.500 ha que la ley exigía en esos casos dado que el lote contaba con 3.573 ha $400 \mathrm{~m}^{2} .{ }^{73}$ Solo un mes más tarde el expediente

71 AINRA.SC, exps. 17951, 14024 y 14089.

72 AINRA.SC, exp. 17951, f. 22.

73 Cuestión que fue señalada durante la revisión del expediente realizada en 1996 que concluyó, entre otras cuestiones, que en realidad hubiera debido ser declarada empresa ganadera, en Ibidem, ff. 35-36. 
se hallaba ya en la sede central del CNRA que, en su sesión del 14 de marzo sucesivo, confirmó la sentencia que fue ratificada por el presidente Adolfo Siles Salinas, por resolución suprema 149189 de 4 de mayo de $1969 .^{74}$

La segunda demanda había sido presentada tres años antes, el 6 de abril de 1966, por Mariano Justiniano Ruiz, probablemente hermano del anterior, natural y vecino de Santa Cruz, quien declaró ser agricultor y ganadero. La solicitud, realizada a través del abogado Rosendo Cuéllar M., ${ }^{75}$ afectaba a la dotación y consolidación del fundo ganadero El Cinco, establecido en El Puente, cuya superficie era de 2.450 ha y que el demandante declaró, estaba trabajando «en posesión pacífica y continuada» desde hacía varios años (cuatro años «más o menos» según el acta de la audiencia de inspección ocular), fórmula similar a la usada por Fernando Justiniano con cuyas tierras colindaba por el este; el fundo contaba con aprovisionamiento de las aguas procedentes del arroyo del Tigre y la aguada de La Poza de las Capiguaras. La explotación contaba con 620 vacunos, 15 reproductores de raza cebú, 30 caballares y un número indeterminado de aves de corral; disponía de corrales y chiqueros para el ordeño, bretes para la vacunación, potreros con una extensión de 70 ha con pastos cultivados, y cultivos agrícolas para el consumo de la hacienda; además, tenía alojamientos para la familia y los asalariados que contrataba para la realización de trabajos temporales. Los productos obtenidos (queso, mantequilla y reses) eran comercializados tanto en el ámbito local guarayo como en el mercado cruceño. ${ }^{76}$

El juez Jorge Aponte Barroso resolvió favorablemente la petición de Justiniano Ruiz dos meses más tarde (Santa Cruz, 7 de junio de 1966) y calificó el fundo de mediana propiedad ganadera. Remitido el expediente a la sede cruceña del CNRA y más tarde a la sede central, la sala primera del Consejo aprobó la sentencia inicial en noviembre del mismo año; algunos meses más tarde (La Paz, 6 de agosto de 1967), el presidente de la república, René Barrientos Ortuño, firmó la resolución suprema 143271 dando paso a la expedición del título correspondiente. ${ }^{77}$

74 Aprobación del CNRA y resolución en Ibidem, ff. 30 y 32.

75 Rosendo Cuéllar M. había estado al frente de la Jefatura Departamental del CNRA en Santa Cruz pocos años antes y, sin duda, conocía todos los entresijos legales y disponía de las relaciones que facilitarían la resolución favorable de las solicitudes llegadas al juzgado agrario cruceño.

76 En realidad, el lote estaba compuesto por dos puestos ganaderos El Cinco y El Despojo, como se recoge también en la sentencia. La solicitud fue firmada el 5 de abril de 1966 y presentada al día siguiente en el juzgado agrario, en AINRA.SC, exp. 14024; la solicitud y el acta de audiencia en ff. 1-2 y 6-7 respectivamente.

77 Auto de vista y resolución suprema en Ibidem, ff. 20-21. 
La tercera solicitud fue la presentada el 21 de junio de 1966, solo quince días más tarde que la anterior, por Hermes Justiniano Moreno (hijo y sobrino de los dos demandantes anteriores, nacido en Santa Cruz) y también por mediación del abogado Rosendo Cuéllar M. En esta ocasión el demandante solicitó la «inafectabilidad y consolidación» del fundo Los Puquios (territorio jurisdiccional de El Puente), cuya extensión aproximada era de 2.500 ha, que declaró haber comprado a Mariano Justiniano Ruiz. Hermes Justiniano dijo haberse «posesionado» de las tierras desde hacía tiempo aunque no había podido realizar la solicitud de la dotación por estar ocupado en el fundo y la lejanía de la capital cruceña, sede del juzgado agrario móvil. El establecimiento, que estaba atravesado por el río Limones, albergaba a 430 vacunos mestizos, 32 caballos, 70 cabríos, 57 ovinos, gran cantidad de porcinos y aves de corral; además, contaba con potreros alambrados en una extensión de 87 ha, y cultivos varios para el consumo de la hacienda en una superficie de 17 ha. La mano de obra utilizada era la del solicitante con el concurso de asalariados que, inicialmente, se dijo eran eventuales, aunque la sentencia señaló que el fundo contaba con cinco peones vaqueros permanentes. Justiniano Moreno, tras sugerir al topógrafo Adolfo Camacho para el levantamiento del plano y redacción del informe pericial, como había hecho ya Mariano Justiniano, concluyó su solicitud esperando obtener sentencia favorable dado que las tierras baldías necesitaban el «concurso del hombre, capitales, voluntad y esfuerzo». ${ }^{78}$

La audiencia de inspección ocular, presidida por el juez Alfredo Eid Otazú y realizada pocas semanas después, registró que la compra se había realizado en 1964 por el valor declarado de 5.000 pesos bolivianos. ${ }^{79}$ La escritura de compraventa permite plantear la hipótesis que el anterior poseedor (M. Justiniano Ruiz) no había realizado explotación alguna del fundo. ${ }^{80} \mathrm{El}$ juez dictó fallo favorable y declaró «inafectable» las tierras del fundo Los Puquios a las que calificó de mediana propiedad ganadera. ${ }^{81}$ Tras

78 AINRA.SC, exp. 14089, f. 1r-v.

79 Equivalentes aproximadamente a 420 dólares estadounidenses, dato obtenido a partir de https://www.bcb.gob.bo/tiposDeCambioHistorico/archivos/1964.php?anio=1964 [Consultado: $11 / 02 / 2021]$.

80 La compraventa fue escriturada en la notaría del Dr. Víctor Salvatierra de Santa Cruz de la Sierra el 2 de agosto de 1966, en AINRA.SC, exp. 14089, ff. 11-12. El documento permite saber, además, que el vendedor Justiniano Ruiz había comprado dicha propiedad a José Parada Pinto solo siete meses antes, el 20 de enero de 1966, lo que a todas luces parece una acción puramente especulativa, aunque se me escapan los detalles de la misma en este caso específico.

81 Sentencia en Ibidem, ff. 20-22v. 
la revisión del expediente, la sala primera del CNRA paceño aprobó, el 11 de noviembre de 1966, el auto de vista correspondiente que dio paso a la resolución suprema 143266 firmada por el presidente René Barrientos Ortuño de 6 de agosto de $1967 .{ }^{82}$

\section{Reflexiones finales}

A partir de las informaciones y los datos recabados en esta investigación se puede afirmar, en primer lugar, que la reforma agraria llegó a Guarayos inmediatamente después de la aprobación de la ley; que alrededor del $50 \%$ de las solicitudes de dotación y/o consolidación de tierras presentadas a los juzgados agrarios móviles de Santa Cruz, desde 1957 hasta 1970, fueron realizadas por empleados y colonos llegados, bajo la administración de la Delegación, más tarde Intendencia Delegacional de Guarayos, a partir de 1938. Estos individuos, procedentes en su mayoría de diversas provincias cruceñas, habían conformado el embrionario grupo dirigente en el ámbito local guarayo tras ocupar tierras y obtener títulos provisionales de las mismas a lo largo de la década de 1940. Fueron los miembros de este grupo quienes, tras la aprobación de la reforma agraria estuvieron en condiciones de explotar la potencialidad económica de la región ya desarrollando actividades agropecuarias directamente, ya haciendo de la tierra objeto de especulación. ${ }^{83}$ Las tierras que provocaron mayor interés de los solicitantes fueron las situadas en las zonas cercanas a Ascensión y El Puente, poblaciones que se hallaban en el camino existente entre Santa Cruz y Trinidad.

En segundo lugar, fueron numerosos los miembros de aquel inicial grupo dirigente carai que, al amparo de la ley agraria y no obstante los límites impuestos por la misma, se hicieron con el control de grandes extensiones de tierras e hicieron de la posesión de las mismas una de las bases de su poder. Ello fue posible, entre otras razones, porque miembros de una misma familia (esposos, padres e hijos, hermanos, sobrinos) devinieron titulares de fundos, situados frecuentemente en el mismo cantón y muchos de los cuales eran colindantes. Por ahora, y a falta de averiguar el parentesco

82 Auto de vista y revisión jurídica de expedientes en Ibidem, ff. 26r-v y 30 respectivamente.

83 Los indicios encontrados en varios de los expedientes analizados permiten plantear esta hipótesis en varios casos, aunque la confirmación de la misma exige acceder a documentos notariales que por ahora no he localizado. 
de los titulares de muchas de las solicitudes, sí sabemos el importante poder económico alcanzado en el período aquí estudiado por los Guaristi y los Suárez en Ascensión; los Justiniano Ruiz y familiares en El Puente; los Añez en Yotaú y El Puente; los Durán Rojas, Sosa López, Arandia Vaca y Rojas en Yaguarú. Está por dilucidar si, tras las mejoras introducidas en la década de 1970 en la vía carretera existente entre Santa Cruz y Guarayos, y más allá hasta Trinidad, la capital beniana, ese poder se incrementaría o si, por el contrario, sería cuestionado por los nuevos colonos que llegaron a partir de entonces.

En tercer lugar, la gran mayoría de los solicitantes de dotación y/o consolidación de las tierras declararon haberlas ocupado años atrás. Esta afirmación, que presentó diversas variantes, fue una fórmula imprecisa que permitía suponer que la ocupación se había efectuado con anterioridad a 1953, lo que daba derecho a la consolidación siempre y cuando se hubieran efectuado trabajos en el fundo.

En cuarto lugar, las tierras existentes en la región guaraya, ricas en pastos naturales y aptas para el desarrollo de potreros (campos con cultivo de hierba) propició que la mayoría de los lotes dotados y/o consolidados se dedicaran a la explotación ganadera; más del $50 \%$ de estos fueron reconocidos como mediana propiedad, seguidos por la pequeña propiedad ganadera, siendo escasos los dedicados a actividades agrícolas o mixtas. Los fundos ganaderos comercializaron sus productos en el ámbito local guarayo pero, la mayoría de ellos (la mediana propiedad ganadera) destinó su producción de quesos, mantequilla y carne de res a los mercados de la capital cruceña e incluso del interior de la república.

Finalmente, diversos indicadores me llevan a señalar que el acceso a la tierra de los miembros del embrionario grupo dirigente surgido en Guarayos en la década de 1940 se vio facilitada por la existencia de una informal red social y política que se empezó a tejer en aquellos años en torno a los partidos políticos surgidos por entonces en la zona, en particular el Movimiento Nacionalista Revolucionario, al que se sumaron la Falange Socialista Boliviana (FSG) y el Partido de Unión Republicana (PUR) ${ }^{84}$ No obstante los datos recabados sobre las organizaciones políticas en los pueblos guarayos de los años aquí estudiados es aún una tarea pendiente. Es igualmente

84 Me consta que varios de los miembros del embrionario grupo dirigente surgido en Guarayos (Ovidio Barbery, Herminio Peredo, OsmánVaca) se hallaron entre los fundadores del MNR; Román Suárez fue afiliado destacado del PUR y Ricardo Ortiz, además de algunos de los miembros de la familia Añez, integraron las filas de la FSB. 
necesario reconstruir la articulación del tejido social en organizaciones, tales como las centrales campesinas y las juntas vecinales constituidas en el ámbito local guarayo de las décadas de 1950 y 1960.

Recibido, 16 de febrero de 2021 Segunda versión, 17 de julio de 2021

Aceptado, 22 de julio de 2021

\section{Referencias bibliográficas}

Antezana, Luis, Latifundio y minifundio en Bolivia, La Paz, Plural Editores, 2011. Armijo Paz, Gabriela Cinthia, «La justicia agraria en Bolivia, sus avances y proyecciones procedimentales», Revista de la Facultad de Derecho de México, LXVII:269, México, 2017, 175-197.

Arrieta, Mario et al., Agricultura en Santa Cruz. De la encomienda colonial a la empresa Modernizada (1559-1985), La Paz, Instituto Latinoamericano de Investigaciones Sociales, 1990.

Blasier, Cole, «The United States and the Revolution», en Malloy, James M. y Thorn, Richard S. (eds.), Beyond the Revolution. Bolivia since 1952, Pittsburgh, University of Pittsburgh Press, 1971, 53-110.

Bretón, Víctor, ¿La tierra para quien la trabaja? Reforma agraria, desarrollo rural y crisis del campesinado en América Latina (1950-1990), Lleida, Universitat de Lleida, 1994.

Chonchol, Jacques, «La reforma agraria en América Latina», en Vargas Vega, John D. (coord.), Proceso agrario en Bolivia y América Latina, La Paz, Ciencias del Desarrollo, Universidad Mayor de San Andrés/Plural Editores, 2003, 205-222.

De Lucca, Manuel y Mamani Pocoata, Mauricio, Reforma agraria en Bolivia, La Paz, Servicio Nacional de Reforma Agraria, 1974.

Díez Cano, Santiago, «Los estudios sobre el poder local: planteamientos y tendencias sobre la investigación reciente», Hispania, LIX:201, Madrid, 1999, 97-111.

Estévez Rubín de Celis, Juan Ignacio, «La hegemonía revolucionaria en Bolivia: el MNR y La Revolución de 1952», Reflexión Política, 21:43, Bucaramanga, 2019, 23-35.

Gallichio, Enrique y Camejo, Alejandra, Desarrollo local y descentralización en América Latina. Nuevas alternativas de desarrollo, Montevideo, Diputación de Barcelona/Centro Latinoamericano de Economía Humana, 2005.

García Jordán, Pilar, «"De la colonización depende el porvenir de la República”. Una historia de la colonización en Bolivia, 1825-1935», Anuario de estudios bolivianos, archivísticos y bibliográficos, Sucre, 2000, 53-106. 
García Jordán, Pilar, Cruz y arado, fusiles y discursos. La construcción de los Orientes en el Perú y Bolivia, 1820-1940, Lima, Instituto Francés de Estudios Andinos/Instituto de Estudios Peruanos, 2001.

García Jordán, Pilar, El Estado propone, los carai disponen y los guarayos devienen ciudadanos. El impacto de la secularización en Guarayos, 1939-1953, Cochabamba, Itinerarios editorial/Instituto Latinoamericano de Misionología, 2015.

Gill, Lesley, Peasants, Entrepeneurs and Social Change. Frontier Development In Lowland Bolivia, London, Routledge, 1987.

Gómez, Sergio, «Las tierras y las reformas agrarias en América Latina: Una mirada al pasado y perspectivas», en Fernandes, Bernardo Mançano et al., La actualidad de la reforma agraria en América Latina y el Caribe, Buenos Aires/São Paulo, CLACSO/Fundãçao Perseu Abramo, 2018, 205-231. Disponible en: https://doi.org/10.2307/j.ctvnp0jt4 [Consultado: 20/06/2021].

Gotkowitz, Laura, La revolución antes de la Revolución. Luchas indígenas por tierra y justicia en Bolivia 1880-1952, La Paz, Plural Editores/Fundación Programa de Investigación Estratégica en Bolivia, 2011.

Guiteras Mombiola, Anna, Warisata en la selva. El núcleo escolar selvícola de Casarabe entre los sirionó, 1937-1948, Barcelona, Edicions de la Universitat de Barcelona/Taller de Estudios e Investigaciones Andino-Amazónicos/Instituto Latinoamericano de Misionología/Itinerarios Editorial, 2020.

Gwarayu mba'ekwasa. Saberes del Pueblo Gwarayu, Santa Cruz, Ministerio de Educación/Centro de Investigación y Promoción del Campesinado, 2006.

Heath, Dwight B.; Erasmus, Charles J. y Buechler, Hans C., Land Reform, and Social Revolution in Bolivia, New York, Frederick A. Praeger, 1969.

Iuliano, Rodolfo, «Perspectivas clásicas y contemporáneas sobre la estratificación social: Aportes de análisis de clase y de la perspectiva de las élites para el estudio de los estratos superiores», Revista de estudios regionales y mercado de trabajo, 6, La Plata, 2010, 239-262. Disponible en: http://www.memoria. fahce.unlp.edu.ar/art_revistas/pr.4542/pr.4542 [Consultado: 12/01/2021].

Lavaud, Jean-Pierre, El embrollo boliviano: Turbulencias sociales y desplazamientos políticos, 1952-1982, La Paz, Hisbol, 1998.

Londoño Mota, Javier Eduardo, «La frontera: un concepto en construcción», en García, Clara Inés (comp.), Fronteras. Territorios y Metáforas, Medellín, Hombre Nuevo Editores/Instituto de Estudios Regionales, 2003, 61-83.

Machicado, Jorge, Sindicalismo y el Sindicato en Bolivia, Sucre, Universidad San Francisco Xavier, 2010. Disponible en: http://www.adapt.it/boletinespanol/ fadocs/NL_3_26.pdf [Consultado: 7/01/2021].

Nobbs-Thiessen, Ben, Landscape of migration: mobility and environmental change on Bolivia's tropical frontier, 1952 to the present, Chapel Hill, University of North Carolina Press, 2021. 
Osorio Silva, Ligia María, «Tierras nuevas y la construcción del estado en Brasil y Argentina», América Latina en la Historia Económica. Revista de Investigación, 25, México, 2006, 43-71.

Pacheco, Pablo y Miranda, Hugo, Las tierras bajas de Bolivia a fines del Siglo XX, La Paz, Fundación Programa de Investigación Estratégica en Bolivia, 2001.

Padua, Jorge y Vaneph, Alain, Poder local y poder regional, México D. F., El Colegio de México/Centro de Estudios Mexicanos y Centroamericanos, 1986.

Pereira Soruco, Hugo, Sociología de la historia del pueblo guarayo en su realidad actual, Santa Cruz, Editorial Litera Viva, 2009.

Reboratti, Carlos E. «Fronteras agrarias en América Latina», GEOcrítica. Cuadernos críticos de Geografía Humana, 87, Barcelona, mayo 1990. Disponible en: http://www.ub.edu/geocrit/geo87.htm [Consultado: 20/06/2021].

Romero Bonifaz, Carlos, «La reforma agraria en las tierras bajas de Bolivia», en Vargas Vega, John D. (coord.), Proceso agrario en Bolivia y América Latina, La Paz, Ciencias del Desarrollo, Universidad Mayor de San Andrés/Plural Editores, 2003, 83-125.

Romero Bonifaz, Carlos, La tierra como fuente de poder económico, político y cultural, Santa Cruz, International Work Group for Indigenous Affairs, 2008.

Romero Bonifaz, Carlos y Betancur, Ana, «El proceso agrario en Bolivia», Asuntos Indigenas, 2:2, Bolivia, International Work Group for Indigenous Affairs, 2002.

Sandoval Arenas, Carmen et al., Santa Cruz: economía y poder, 1952-1993, La Paz, Fundación Programa de Investigación Estratégica en Bolivia, 2003.

Soruco, Ximena, «De la goma a la soya: El proyecto histórico de la élite cruceña», en Soruco, Ximena (coord.), Los barones del Oriente, Santa Cruz, Fundación Tierra, 2008, 1-100.

Ticona, Esteban, «La Revolución Boliviana de 1952 y los pueblos indígenas», Revista Temas Sociales, 25, La Paz, 2004, 1-14. 